\title{
Reference Architecture for Collaborative Design
}

\author{
C.Y. Huang, T.T. Yang, W.L Chen, S. Y. Nof
}

\author{
Chin-Yin Huang \\ Department of Industrial Engineering and Enterprise Information \\ PO Box 985, Tunghai University, Taichung 407, TAIWAN \\ E-mail: huangcy@ie.thu.edu.tw \\ Tung-Ting Yang \\ HTC Corporation \\ No.23, Singhua Rd., Taoyuan City, Taoyuan 330, TAIWAN \\ E-mail: anne7349@ hotmail.com

\section{Wu-Lin Chen} \\ Department of Computer Science and Information Management \\ Providence University, Taichung 407, TAIWAN \\ E-mail: wlchen@pu.edu.tw

\section{Shimon Y. Nof} \\ School of Industrial Engineering \\ Purdue University, 315 N. Grant Street, W. Lafayette, IN 47907-2023, USA \\ E-mail: nof@purdue.edu
}

\begin{abstract}
:
Issues and themes of Collaborative Design (CD) addressed by research done so far are so extensive that when running a project of collaborative design, people may lack directions or guidelines to support the whole picture. Hence, developing reference architecture for $\mathrm{CD}$ is important and necessary in the academic and the empirical fields. Reference architecture provides the systematic, elementary skeleton and can be extended and adapted to diverse, changing environments. It also provides a comprehensive framework and enables practices implemented more thoroughly and easily. The reference architecture developed in this re-search is formed along three dimensions: decision aspect, design stage, and collaboration scope. There are five elements in the dimension of decision aspect: (1) participant, (2) product, (3) process, (4) organization, and (5) information. The dimension of design stage includes three stages: (1) planning and concepting, (2) system-level design and detail design, and (3) testing and prototyping. The dimension of collaboration scope includes three types of collaboration: (1) cross-functional, (2) cross-company, and (3) cross-industry. Because of the three reference dimensions, a cubic architecture is developed. The cubic reference architecture helps decision-makers in dealing with implementing a $\mathrm{CD}$ project or activity. It also serves as a guideline for $\mathrm{CD}$ system developers or people involved in the design collaboration to figure out their own responsibility functions and their relations with other members. Demonstration of how to use the reference architecture in developing design collaboration activities and specifying the details for cross-company $\mathrm{CD}$ is also provided in this research.
\end{abstract}

Keywords: collaboration reference model, collaboration support, communication, cross-company design collaboration, design management, design stage, information system. 


\section{Collaborative Design}

\subsection{Definition and Issues}

Research about collaboration activities has become popular from the 1990s with the emergence of the Internet and following the increasing requirements and benefits of concurrent design [20] [24]. Collaboration covers an extensive domain that includes a large variety of concerns and issues, from product development collaboration to customer relations management, e-service and e-commerce [23] [10] [50] [7] [32]. Specifically, the core arena of the research reported in this article focuses on Collaborative Design (CD) under the key subject of product development collaboration. Collaboration is a process in which entities share information, resources and responsibilities to jointly plan, implement, and evaluate a series of activities to achieve a common goal. It implies a group of entities that work together and enhance the capabilities of each other. Collaboration involves mutual engagement of participants to solve a problem together [31]. Related research topics are summarized in Table 1.

Table 1 Research Topics of Collaborative Design

\begin{tabular}{|l|l|}
\hline Topic of CD & References \\
\hline $\begin{array}{l}\text { Methods and models } \\
\text { developed for CD }\end{array}$ & $\begin{array}{l}\text { Klein [21]; Brelinghoven [4]; } \\
\text { Witzerman and Nof [52]; Huang and Nof [17] } \\
\text { Khanna et al. [20]; Jin and Lu [18]; } \\
\text { Abdalla [1]; Mahesh et al.[29]; } \\
\text { Panchal et al.[34]; Wang et al. [51] }\end{array}$ \\
\hline $\begin{array}{l}\text { Collaborative environment } \\
\text { developed to facilitate or support CD }\end{array}$ & $\begin{array}{l}\text { Lara and Nof [25]; Hao et al. [13]; Li and Su [26]; } \\
\text { Pappas et al.[36]; Robin et al. [39]; } \\
\text { Alvares and Ferreira [2]; Tian et al. [45]; } \\
\text { Tseng et al. [47] }\end{array}$ \\
\hline Knowledge/ intelligent capital of CD & $\begin{array}{l}\text { Thomas and Baker [44]; Chiang et al. [8]; } \\
\text { Huang [16]; Panchal et al. [35]; Chira et al. [9] }\end{array}$ \\
\hline $\begin{array}{l}\text { Management issues of CD (including } \\
\text { social/organizational aspects) }\end{array}$ & $\begin{array}{l}\text { Noori and Lee [33]; Ceroni and Velasquez [6]; } \\
\text { Pilemalm et al. [37]; Shiau and Wee [41]; } \\
\text { Slimani et al. [42] }\end{array}$ \\
\hline $\begin{array}{l}\text { Applications or case } \\
\text { examples of CD }\end{array}$ & $\begin{array}{l}\text { Tang [43]; Hao et al.[13]; Ceroni and Nof [7] } \\
\text { Trappey and Hsiao [46]; Chung and Lee [12] }\end{array}$ \\
\hline
\end{tabular}

\subsection{Development Process}

Traditional Computer-Aided-Design (CAD) system improves the efficiency and effectiveness of design information interchanging and speeds up the concept design visualization process, but the way of it only supports individual designers in their design activities and does not support the trend and business surroundings. Evolved collaborative CAD system conquered this problem enabling multiple designers to work on a design together, such as system called Computer Supported Cooperative Work (CSCW). With IT such as Internet support and Web 2.0 etc., web-based CAD systems advance to facilitate extensive application of CD. Web-based CAD system such as C-DeSS [22] integrates web-based multimedia tools with web-based model display. This communication platform allows multiple users from geographically distributed locations to share their design concepts, innovations, and models through Internet technology [27]. 


\subsection{Components}

An interaction model between factors influencing the design system was developed by Robin et al. [40]. The key interest of their model is to present and define all elements which influence a design system and interactions between them. The objective is to support engineering management according to structuring of decisions making. From this fundamental map, it describes the context of product design system and integrates all these elements, including actor, process, organization, product, knowledge, and environments. Eight kinds of links within all of the six elements compose research contents of design topics.

\subsection{Challenges}

Reference architecture is a necessity among organizations that collaborate at multiple levels. Examples such as the Boeing 787 Dreamliner project design complexities and challenges could be cited to illustrate the need for a useful, well-defined collaboration architecture to avoid costly mistakes in the design process. Eight issues that need to be conquered regarding CD framework are [35]:

1. Adaptability to network architecture changes or malfunction,

2. Usability on heterogeneous platforms with heterogeneous operating systems,

3. Heterogeneous languages for different agents (semantic interoperability),

4. Capability to transmit message and data changes (semantic interoperability),

5. Rapid configuration of the product realization environment (considering reasons like time-tomarket, and so on),

6. Minimizing the impact of agent service changes,

7. Readiness for future expansion, and

8. Readiness for discrepancy of process information.

The above eight issues can be used as a checklist for the completeness of the reference architecture developed. In addition, the reference architecture is viewed as an approach to establish collaboration requirements planning, the first principle of Collaborative Control Theory, CCT [32].

\section{Reference Architecture and Factors}

Functions of reference architecture include: (1) showing the evolution of development, (2) guiding all the parties from each of the different disciplines involved, (3) incorporating several different views, (4) presenting a method for the breakdown of all system functions to their inherent generic functions and tasks [38]. To develop reference architecture for $\mathrm{CD}$, factors of three layers are considered: elementary factors, qualified factors, and advanced factors.

\subsection{Elementary Factors}

Two substances taken into consideration are industry characteristics and the infrastructure of information system. The former indicates that involved participants focus more on the product and process aspect in improving efficiency and effectiveness of design process. The latter one means level or completeness the infrastructure of IT can support. The IT infrastructure primarily aims at fundamental information system such as PDM or Collaborative Product Definition Management (CPDM) and adoption of software such as CAD or CAPP to facilitate the design process. 


\subsection{Qualified Factors}

Based on the elementary factors, four CD qualified factors are considered in this research:

1. Data repository or database with profound contents: It stores the entities of the virtual world together with their attributes, and the database should include functions such as information storage and data retrieval.

2. 3D virtualization tool for product design: Tool such as Dynamic UI Generation, CAD-CAE System, and 3D editor. This tool is a virtual product manager that provides users with a local as well as collaborative desktop GUI.

3. Connecting systems for communication and interchanges: These are systems connected with one another via LAN or Internet. Therefore Internet, web browser or process diagram tool may be practical enablers of $\mathrm{CD}$, used to model a product realization process and then invoke the available agents integrated into the collaboration support framework. The cooperative support platform is another example of a connecting system [28].

4. Powerful Application Service Provider (ASP) Server or core application: This service provides functionality for dynamic and stable loading, processing and saving the design-related objects of the virtual world, which may originate from diverse collaborating designers and their agents.

\subsection{Advanced Factors}

With basic equipment as elementary and qualified factors, discussions of CD will be advanced to another connected frame. The CD Cube, which is composed of three key dimensions, as defined in the next section, focuses more on the advanced factors which enable the systematic implementation of effective $\mathrm{CD}$. In the decision dimension, five deciding elements are specified; in the design stage dimension, different characteristics of $\mathrm{CD}$ follow the classification of each design stage; finally, in the collaboration scope dimension, models of $\mathrm{CD}$ are defined and discussed with various boundaries set for each scope.

\section{Reference Architecture for Collaborative Design}

First, a conceptual depiction of the contents and dimensions to model a CD activity is introduced (Figure 1). To structure a CD reference architecture, the situation of proposed CD is first clarified, including the actors involved, the target objectives for collaboration, available competences in the $\mathrm{CD}$ activity, and available resources. Next, CD process model, corresponding CD organization type to carry out the project, information interchange mechanism, and the collaborative design stage and scope which are involved have to be specified. Considering all of these issues, the $\mathrm{CD}$ framework containing taxonomy of each composing elements, principles for CD initiator, and other subjects can be developed.

\subsection{Framework}

Based on the previously discussed background, a $3 * 5 * 3 \mathrm{CD}$ framework is developed (Figure 2). With which, one can figure out the current status of collaboration, or see if all relevant details have already been taken into considerations. For example, once the $\mathrm{CD}$ of product concept design is decided to be originated across two extended companies, then the circumstances taken into considerations should fall on to the left bar of middle surface of the cube. Furthermore, if the CD is carried out through the product design lifecycle from planning to production ramp-up, then the middle level surface would be the proposed boundary. 


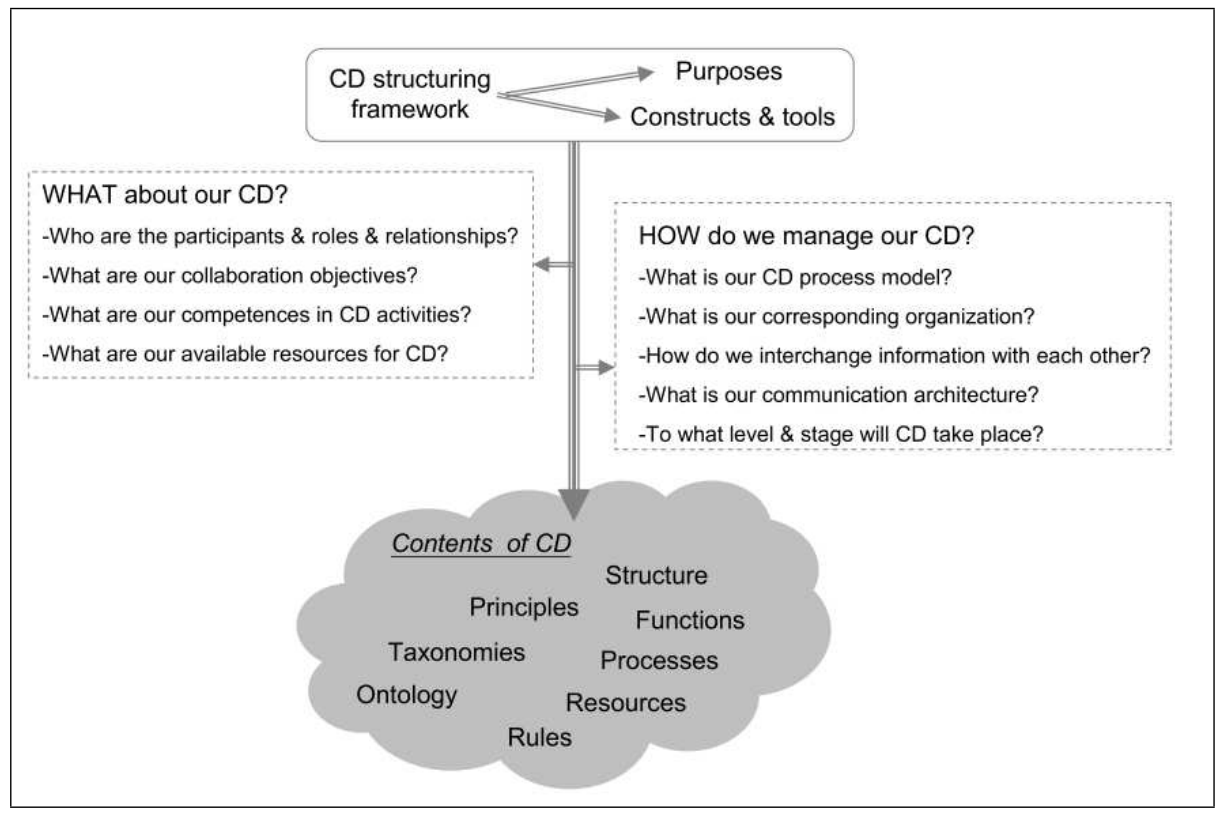

Figure 1: Content of CD Reference Architecture

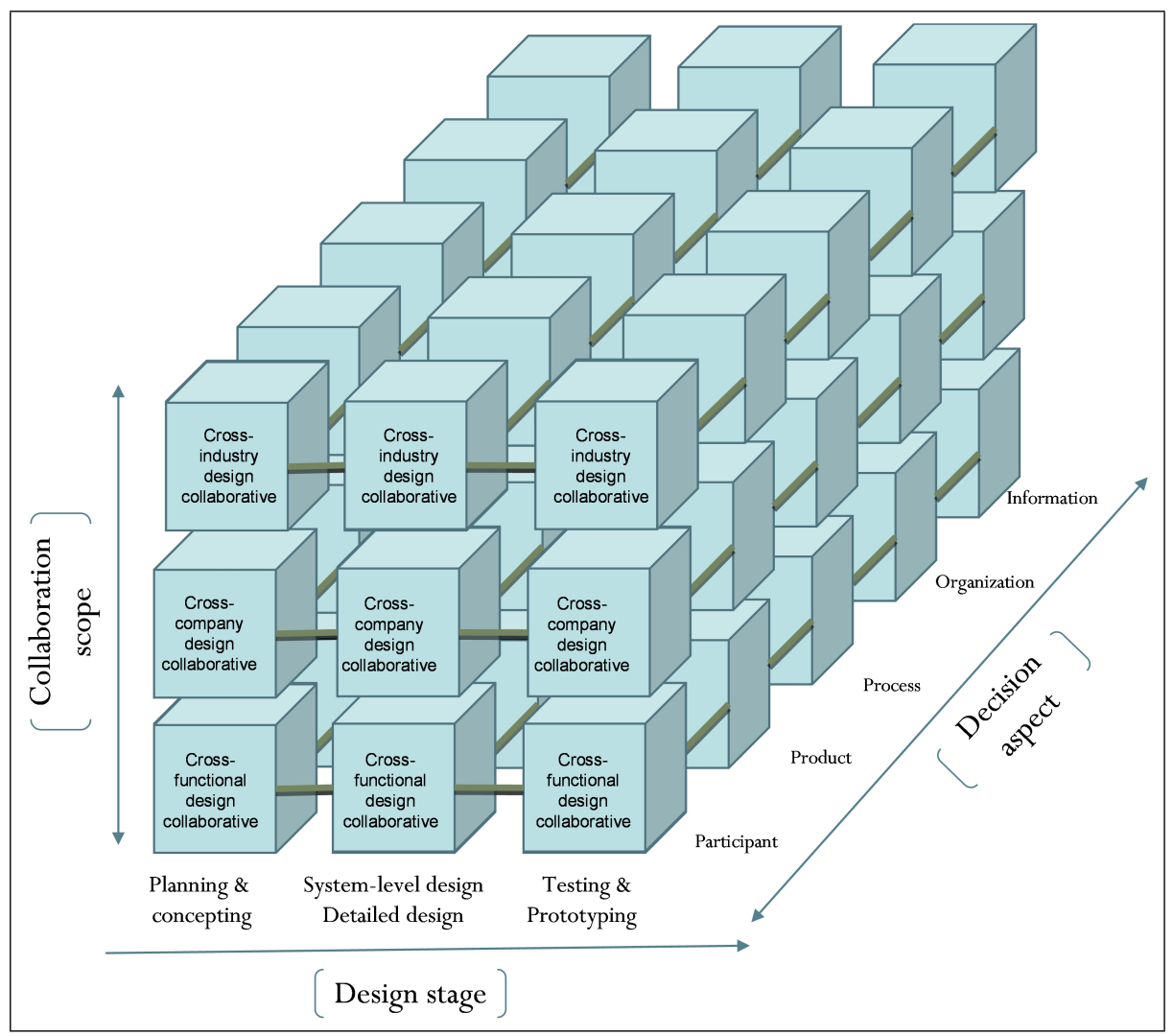

Figure 2: Reference Architecture of Collaborative Design 


\subsection{Decision Aspect}

In the dimension of decision aspect, five elements are specified in a CD project: participant, product, process, organization, and information.

\section{Participant}

With the horizontal axis of deepness and vertical axis of extensiveness in collaborative activities, a two-by-two matrix is produced. This matrix clarifies the participant types involved in CD in a view of primary actors for decision making (Figure 3 (a)). Based on the two axes, four types of CD participants, which are major, niche, compatible, and minor players, are specified.

Major Player represents deep connection of cooperators and advanced extensiveness of the proposed collaboration. This type of participant focuses on fundamental CD or NPD (new product development/ design), and is prone to adopt the manner of integrated corporation, joint venture (JV), or extended enterprise (EE).

Niche Player represents deep connection of cooperators but limited extensiveness of proposed collaboration. This type of participant possesses certain dominant or specific skills or technology in which primary actors are interested. For this reason, corresponding collaboration target would be professional New Product (NP) or under the mature competence market applying the manner of VE (virtual enterprise), $\mathrm{VO}$ (virtual organization), etc.

Compatible Player represents shallow connection of cooperators but advanced extensiveness of proposed collaboration. This type of participant is capable of providing non-fundamental but customized or domain-specific NP with manner of contractual agreement, which is the same manner applied by Minor Player (below). The Compatible and Minor Players, however, can be discriminated by the product or service they collaboratively design. Consider the example of Foxconn(R), although Foxconn seems like a Minor Player providing fundamental OEM jobs to many other potential competitors for their customers, it performs with solid status in the market for its own specific or customized capability to fulfill the needs of customers. Hence, it is considered as a Compatible Player.

Minor Player represents shallow connection of cooperators with limited extensiveness of proposed collaboration. This type of participant has the most potential risks for being replaced by competitors easily for lack of its own sustainability with others or for lack of close relations or extraordinary capability. Minor Players usually participate in general/routine NPD or take the OEM role to their ODM/OBM customers.

\section{Product}

The vertical axis represents the market status consisting of current market and new market, and the horizontal axis represents the current technology and new technology. First, it is hypothesized that the product is in the status of current market using current technology. Then, four main product types can be defined in view of product development projects under this structure, as shown in Figure 3 (b). When corporation strategy is the current market-current technology, incremental improvement to existing products would be the product type. When corporation strategy is the new market-current technology, derivative of existing product platforms would be the product type. When corporation strategy is the current market-new technology, new product platforms or new product generation/upgrade would be the product type. In this region, it is possible to be still in the same product family but using different product platform in product realization. On the other hand, new product generation/upgrade type can also be introduced in this corner, for it also to be under the same product family with different or update technology. When corporation strategy is the new market-new technology, fundamentally new products would be the product type. 


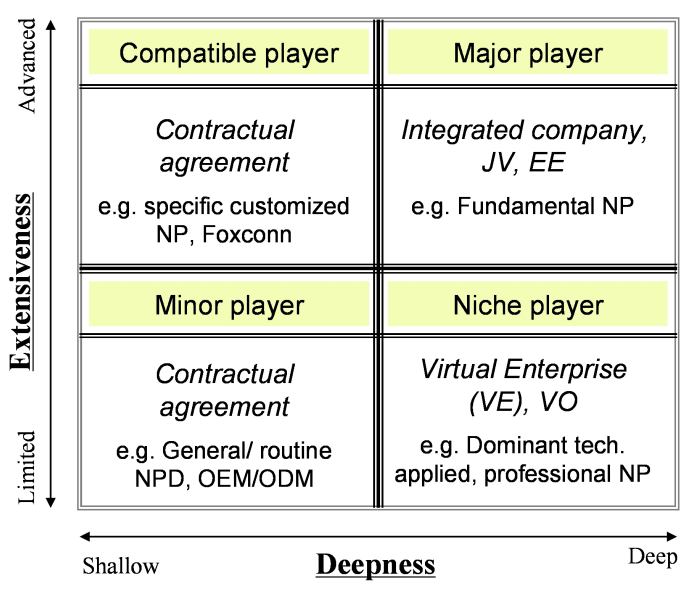

(a)

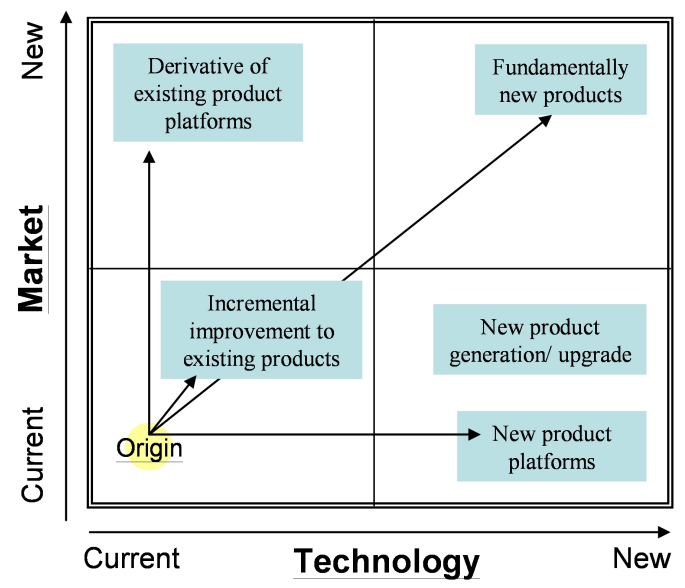

(b)

Figure 3: (a) CD participant classification matrix, (b) Strategy of product type

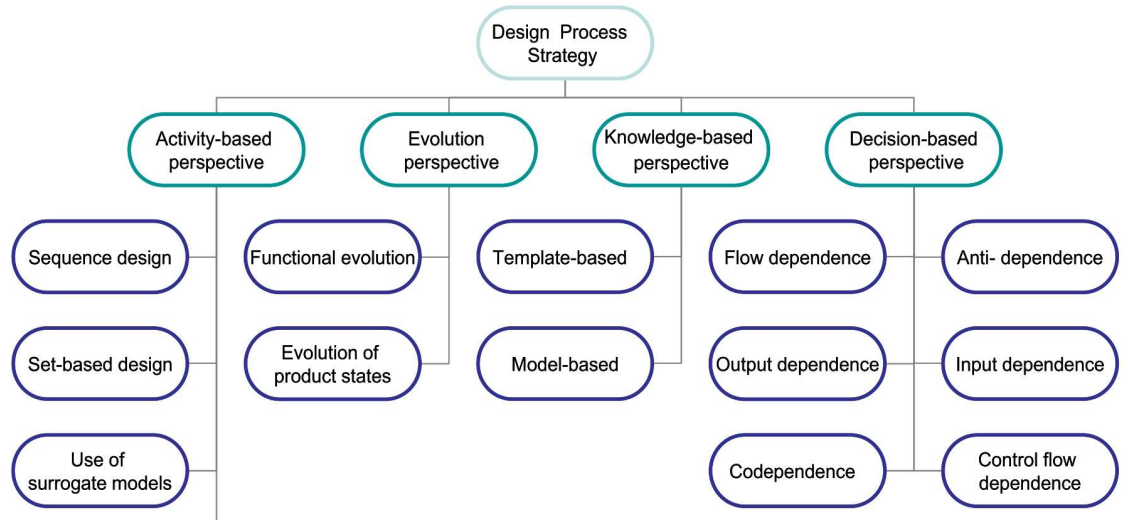

Figure 4: Process Taxonomy

\begin{tabular}{|cccc|}
\hline \multirow{2}{*}{$\begin{array}{c}\text { Tough } \\
\text { Collective }\end{array}$} & Power of CD project leader & Weak \\
$\stackrel{\text { Project organization }}{\longrightarrow}$ & Mediatory organization & Functional organization \\
\hline
\end{tabular}
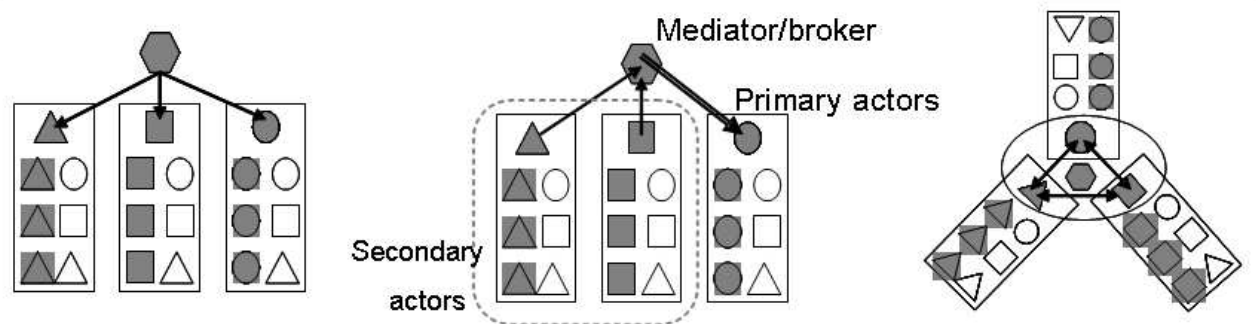

Figure 5: Organization type taxonomy 


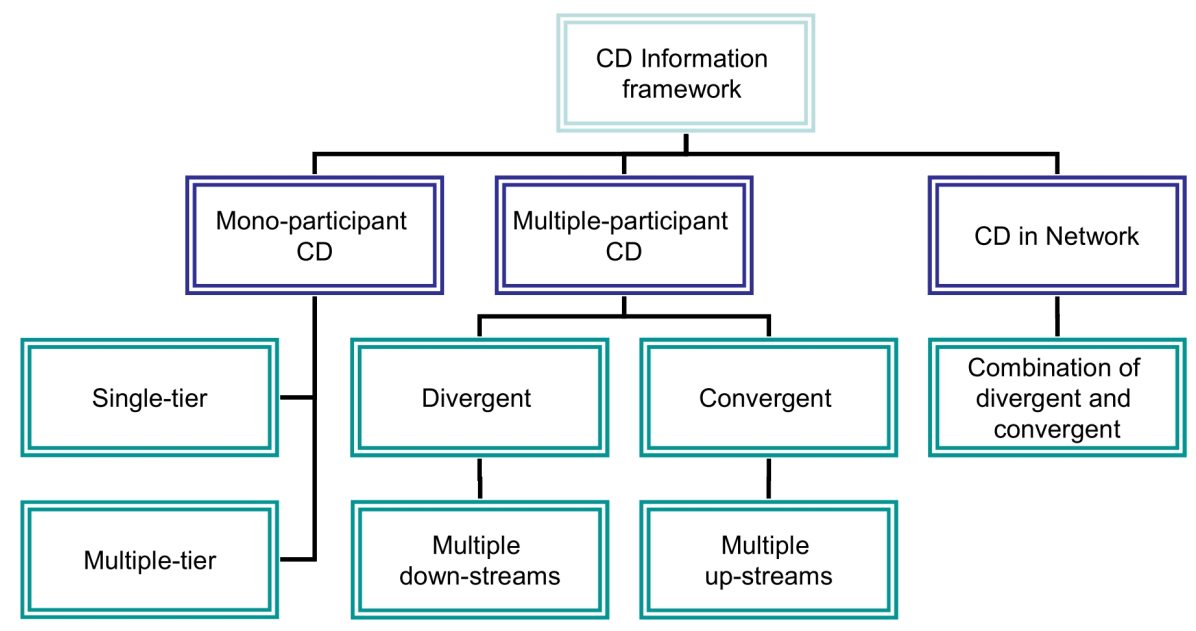

Figure 6: CD Information framework

\section{Process}

After reviewing research regarding process types of design, product development and collaboration, an overview aspect of design process strategy is developed. Under the design strategy domain, four perspectives are concluded: activity-based, evolution, knowledge-based, and decision-based. These four comprise the design process taxonomy of CD (Figure 4).

\section{Organization}

A structured organization can facilitate design communication and consequently contribute to the success of the design project [11]. With different types of CD cooperation, organizational changes are necessary to be adopted for better fitness of design process rearrangement and coordination between entities of collaboration. Combining theories proposed by Hayes [14], Ulrich and Eppinger [48] and Chiu [11], taxonomy of CD organization is presented in Figure 5. Three organization categories in the taxonomy can explain considered CD situations and provide a reference. Extended from classical project management organization classification proposed by Ulrich and Eppinger [48], the taxonomy of organization types includes project, mediatory, and functional organization (Table 2).

\section{Information}

By utilizing the organization and participants structures as the interpreting settings, CD can take place in three circumstances, namely mono-participant $\mathrm{CD}$, multiple-participant $\mathrm{CD}$, and network $\mathrm{CD}$ (Figure 6).

\subsection{Design Stage}

Design process can be defined as networks of information transformations from one state to another. The state of information refers to the amount and form of that information that is available for design decision-making [35]. Stages/processes of product design and development can be basically defined as process of Idea/Requirement, Concept Design, Design Build, System Integration, Product Validation, Manufacture Validation, and Mass Production. Ulrich and Eppinger [49] also have similar view on stages/processes of product design and development. They define six steps: planning, concept de- 
velopment, system-level design, detail design, testing and refinement, and production ramp-up. Three significant types of design processes are proposed by Holt [15]:

1. The analytical design process: used when there is little uncertainty about the alternatives, and the outcome is only a modification of something that already exists.

2. The iterative design process: This process is best suited to medium-risk projects such as radical improvements and adopted innovations.

3. The visionary design process: in which the problem cannot be defined precisely and is, perhaps vague at best.

A more precise viewpoint on activities of design is given by Borja de Mozota [3]. They consider a creative process, divided into three main phases: an analytic stage of widening the observation field; a synergistic stage of idea and concept generation; and a final stage of selecting the optimal solution. The creative process comprises of five phases, each of which has a different objective and corresponds with the production of increasingly more elaborate visual outputs.

Table 2 Organization type taxonomy

\begin{tabular}{llll} 
Characteristics & \multicolumn{3}{c}{ Organization type } \\
\cline { 2 - 5 } & Project organization & $\begin{array}{l}\text { Mediatory organiza- } \\
\text { tion }\end{array}$ & $\begin{array}{l}\text { Functional organiza- } \\
\text { tion }\end{array}$ \\
\hline Candidate of CD leader & $\begin{array}{l}\text { From one of the enti- } \\
\text { ties }\end{array}$ & Primary actor & $\begin{array}{l}\text { From one of the enti- } \\
\text { ties or the third party }\end{array}$ \\
\hline Hierarchical power & $\begin{array}{l}\text { Tough, demanding, } \\
\text { powerful }\end{array}$ & $\begin{array}{l}\text { Clear hierarchical re- } \\
\text { lation }\end{array}$ & $\begin{array}{l}\text { Weak/Harmony hier- } \\
\text { archical relations }\end{array}$ \\
\hline Final decision maker & CD leader & $\begin{array}{l}\text { CD leader (primary } \\
\text { actor) }\end{array}$ & All of the entities \\
\hline Power of entities & $\begin{array}{l}\text { Dependent to each } \\
\text { other in decision } \\
\text { making }\end{array}$ & $\begin{array}{l}\text { Independent but de- } \\
\text { pendent to each other } \\
\text { in cross-decision } \\
\text { making }\end{array}$ & $\begin{array}{l}\text { Independent but has } \\
\text { individual belonging } \\
\text { organization }\end{array}$ \\
\hline Collaborative relation & Collective-oriented & $\begin{array}{l}\text { Partnership or sup- } \\
\text { porting relationship }\end{array}$ & Individual-oriented \\
\hline Interface of the entities & $\begin{array}{l}\text { Mutually agreed pro- } \\
\text { tocols }\end{array}$ & $\begin{array}{l}\text { Mediator or broker or } \\
\text { software agent }\end{array}$ & Process integration
\end{tabular}

\section{Planning and Concepting}

In the first design stage, Planning and Concepting, collaboration is basically focusing on the preparation stage ahead of the precise designing practical tasks prior to the next stage. Issues of this stage are primarily about the coordination related to $\mathrm{CD}$ project/process planning and product concept development. These issues include design tasks such as identification of user needs, technical factors, the diverse requirements of the operating environment, product exploration, and concept development. Detailed, interleaved tasks include initial design idea collection, information pooling from the present market, confirmation of customer needs, assessment of new technologies and needs, assessment of market demands, application for forming the design project, gaining permission for triggering following activities, designating product platform and architecture, and proposals of product concept designing. 
Keinonen [19] demonstrates the concept design process which consists of a series of stages, containing information gathering, brainstorming, scenario creation, concepts formation, formalization, evaluation, and final integration with project planning. Basically, the planning and concepting stage is composed of three sub-categories, namely background research, concept generation, and concept evaluation.

\section{System-Level Design and Detailed Design}

In the second design stage, subjects being focused are primarily about the specified design tasks regarding product structure and architecture. CD issues of this stage would be complex for various kinds of coordination related to the design activities occur among the participants, products, process, and organization, through information systems. The second stage contains major design tasks such as product material and technology defined, new product design specifications, system-level design, detailed designs, resource allocation, selected concept design confirmation, current product analysis and market survey, etc. Because various interactions and coordination occur in the $\mathrm{CD}$ activities, conflicts and arguments could occur. Based on Liu et al. [27], there are three types of conflicts: (1) conflicts of a single task (2) conflicts between tasks, and (3) conflicts of system level with different disciplines.

The first type of conflict includes two indications. One indicates the conflicts occur when the design task with different objectives, properties, requirements, or even sharing same resources such as machines for making components, material for manufacturing, etc. The other indicates the conflicts occur when participants updating design description simultaneously, i.e, codependence [20]. For instances, when both of sales A and B are trying to book the same original material C for their own WIP, WIP a and WIP $\mathrm{b}$, with the constraints of limited original material $\mathrm{C}$, conflicts may occur if there is no decision rule or user authority restrictions of the material booking system.

The second type of conflict is related to coordination between activities of design process or agent communication. A typical example could occur for the engineering systems of engine design and airconditioning of Boeing 747. The interaction between these two systems should be taken into consideration together during system-level design to avoid the situation of incompatibility. The solution of the conflicts have been proposed by Khanna and Nof [20] based on a canonical model for the task dependences. The third type of conflict is related to the communication issues of standalone systems. This type of conflict has two indications: interface incompatibility and loss of associated information under the situation of design changes [30]. For example, in the same system-level design stage, electrical engineers and mechanical engineers are both working on the product architecture modeling. They have to deal with the interface incompatibility of geometrical information and the capability of interpreting meta-information of interchanges.

\section{Testing and Prototyping}

In the third stage, major interleaved activities involve preempt production, manufacturing validation, marketing experiments, prototyping production, product evaluation, product refinement, etc. This is the last step along the product design process, but does play an important role to fill up the existing gaps between design and manufacturing stages. To facilitate the integration of different experts and enhance the efficiency of the iterative phases, prototypes are used as cost-efficient visual models. The use of virtual prototypes is especially important in the early phases of product development, to enable time- and cost-efficient decision making [5]. Prototyping can be categorized, however, into physical and digital activities [5].

Physical prototyping is well-known by the name rapid prototyping (RPT) for making it possible to produce physical artifacts directly from CAD model. The most common techniques today, including stereo-lithography (STL), selective laser sintering (SLS), solid ground curing (SGC), and fused deposition modeling (FDM), are mainly used to produce design or geometrical prototypes. To accelerate the development process, technical and functional prototypes are of great importance. Rapid tooling offers 
the possibility of building functional prototypes, and it is possible to build tools rapidly and inexpensively for prototypes in parallel with the product development process.

Physical prototypes, however, are often time- and cost-intensive and thus need to be reduced to a minimum. By integrating CAD technologies, rapid prototyping, virtual reality, and reverse engineering, prototypes can be produced faster and less costly than before. The digital demonstration allows early modification and optimization of the prototype. Furthermore, it leads to cost-saving increase in the variety of prototypes. Additionally, faults concerning fabrication of the product itself can be detected in the early development phase and thus be eliminated without unnecessary expenditures.

An important component of digital prototyping is the digital mock-up (DMU), a purely digital test model of technical product. The objective of the DMU is the availability of multiple views of product shape, function, and technological coherences. This DMU forms the basis on which the modeling and simulation (testing) can be performed and communicated for an improved configuration of the design. The primary digital design model is called the virtual product. The idea is to test the prototype regarding design, function, and efficiency before producing the physical prototype. An enormous advantage of the DMU is the shortening of iteration cycles. Employing the DMU considerably reduces the time-to-market.

\subsection{Collaboration Scope}

The last dimension in the CD reference model is the collaboration scope. Dealing with the scope of $\mathrm{CD}$, we put it into three segments: cross-functional CD, cross-company $\mathrm{CD}$, and cross-industry CD.

\section{Cross-Function}

Cross-functional $\mathrm{CD}$, which is commonly utilized, represents $\mathrm{CD}$ activities taking place within the collaboration scope of one individual enterprise. CD may occur within the design collaboration team composed of designers only, or among multiple-discipline departments/functions containing designers and non-designers. In general, essential participants of cross-functional CD may include project manager, designers, project supporters (non-designers), and system administrator/coordinator.

\section{Cross-Company}

In cross-company $\mathrm{CD}, \mathrm{CD}$ activities occur between two enterprises which may have relation with one another, or are completely individual. Liu et al. [27] define the main characteristics of CD within the scope of cross-company as containing groups of designers, manufacturers, suppliers, and customer representatives, which can be seen as the extended case of cross-functional CD. It should be noted in their definition that the actors involved in this scope of $\mathrm{CD}$ are counted by groups rather than as individuals. Vertical integration and horizontal integration are two views to examine in the cross-company relationships.

In view of vertical integration, $C D$ could be carried out by two enterprises within the same supply chain; members of CD may be responsible for different tasks of the supply chain such as CD of two cooperators with the relationship of ODM and OBM. Or, CD could be carried out by two enterprises of two unrelated supply chains. In this case, $C D$ can be executed by members of the same function in two different supply chains, or by members of complementary functions of two different chains. In more complicated situations, members of CD may include actors of the same and complementary functions from both the same chain and different chains.

In view of horizontal integration, members of $\mathrm{CD}$ do not only belong to different supply chains but also have different industry attributes. These differences render them unable to have complementary collaborative relationships. They may get together not for permanent cooperation but to capture certain instant opportunities, which apply with the concept of virtual enterprises. 


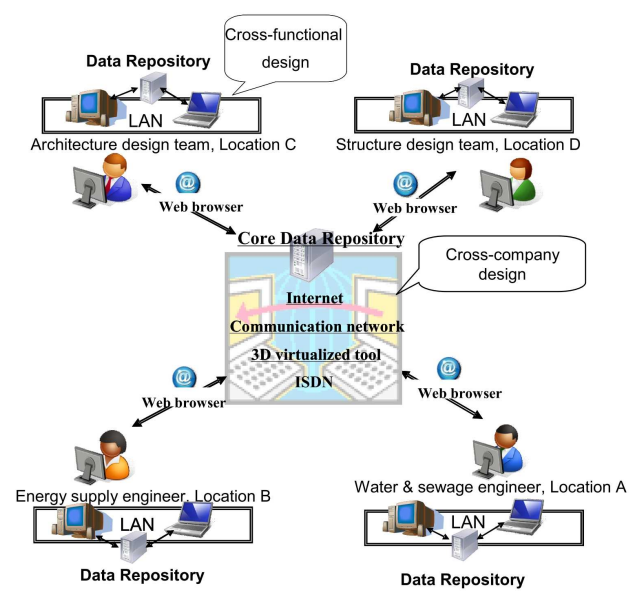

(a)

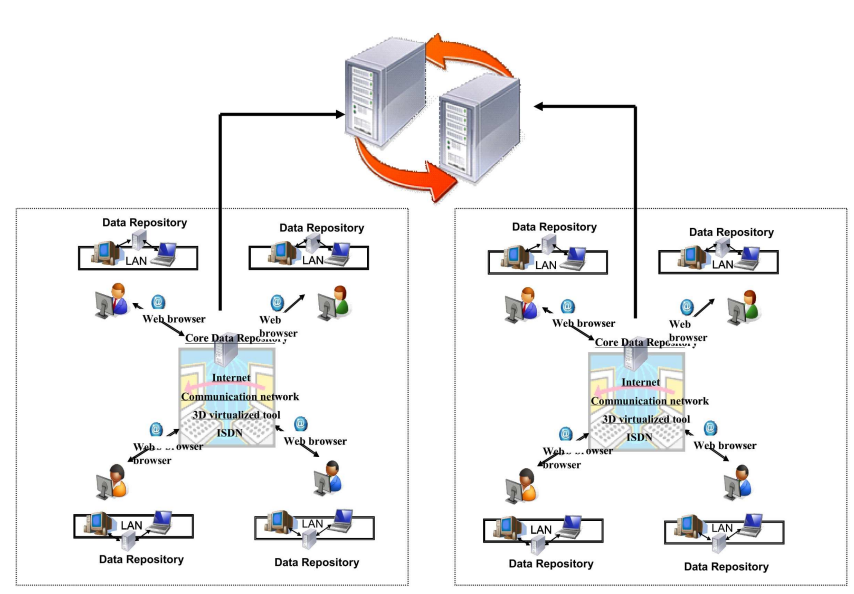

(b)

Figure 7: (a) Communication reference framework (b) Communication reference framework: crossindustry collaboration by a third-party repository

\section{Cross-Industry}

In cross-industry $\mathrm{CD}$, the model is regarded as the extended horizontal integration CD of crosscompany. Considering the product City Storm $(\mathrm{R})$ bicycle, which is the $\mathrm{CD}$ achievement of Giant $(\mathrm{R})$ and $\operatorname{DEM}(\mathrm{R})$, as an example, Giant (a bicycle builder) and DEM (an artifact design company) belonged initially to two different industries, but they cooperate with each other and both focus on their own core competence. Eventually, through CD, both companies create a successful collaborative business.

The relevant communication reference framework is defined to indicate the elementary components of a fundamental CD (Figure 7 (a)). In the framework, there are four CD teams in this network, which are located around the globe, and each of them is responsible for specific tasks of the CD project, which are architecture design, structure design, energy supply engineering, and water \& sewage engineering. To configure $\mathrm{CD}$ activity, each of the $\mathrm{CD}$ members should be equipped with technology and infrastructures including data repository, web browser, process diagram tool, interface mapping/integration tool, and Dynamic User Interface (UI) Generation (application tools). The scenario described above is an example of CD taken with cross-company scope.

In Figure 7 (b), the cross-industry collaboration can be regarded as the extended case of crosscompany collaboration. The most significant difference between Figures 7 (a) and (b) of CD is the interfaces or collaboration platforms on which they communicate with each other. In Figure 7 (b), participants of $\mathrm{CD}$ which come from two different supply chains of diverse industry characteristics may collaborate with each other under the $\mathrm{CD}$ environment supported by a third-party repository, which represents certified criteria for communication among cooperators. In addition to the certified criteria for communication, integration, and exchange, the third-party repository may protect the privacy and security of the cooperating parties which belong to different companies and different industries.

\section{Cross-Company Application of the Reference Architecture}

To demonstrate the CD application of the reference architecture, a cross-company reference model is developed. By horizontally slicing the reference architecture in Figure 2, a cross-company reference model (Figure 8) may be developed for a specific application domain.

In the participant element, two main relation types of $\mathrm{CD}$ participants are designer-to-designer and 


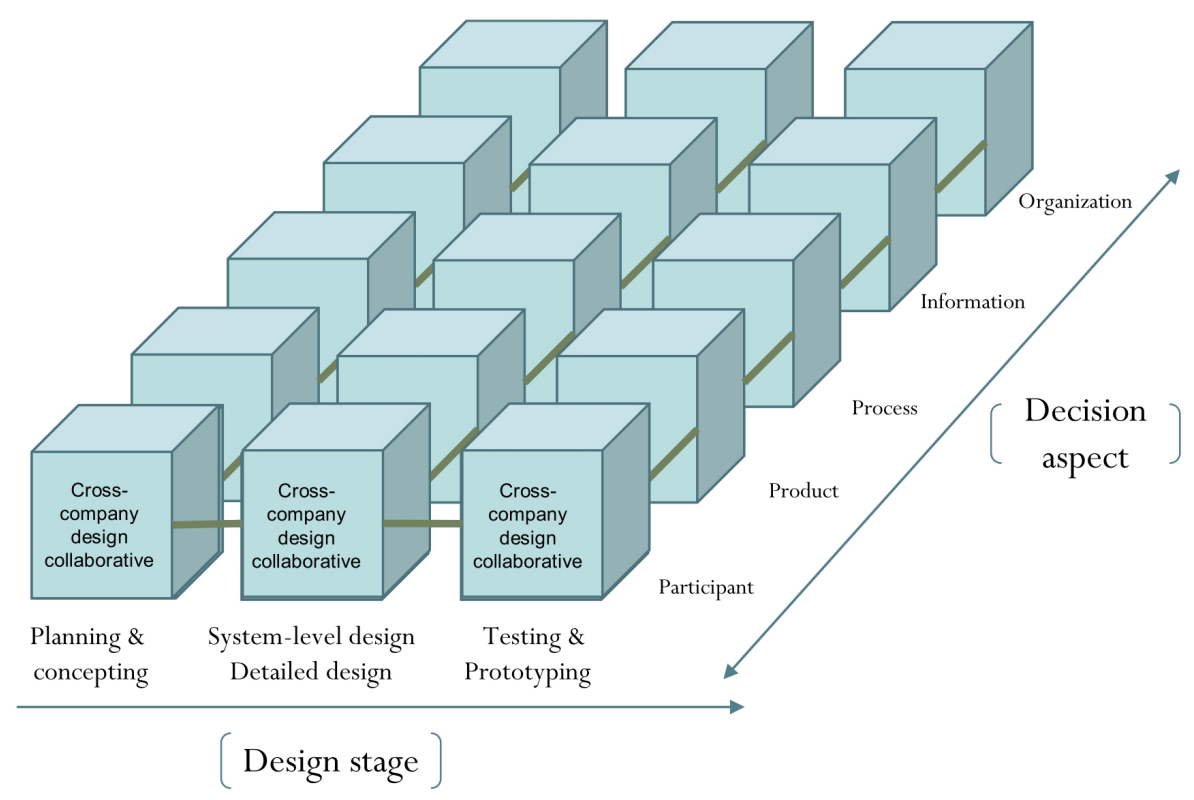

Figure 8: Cross-Company Reference Model

designer-to-non-designer. In the former case, the involved participants can be classified by the CD participant classification matrix in Figure 3 (a). For instance, if the case of the target CD product is Dominant Technology Required, then Niche Player of possessing particular techniques would be included. Examples are an up-stream IC-chip manufacturer such as Intel, or a transmission corporation such as Shimano $(\mathrm{R})$, whose products are the most critical components of bicycle, to all ODM, even OBM such as Giant.

In the product element, $\mathrm{CD}$ with complex and multiple-disciplines team members is more commonly found to be a cross-company CD. Fundamentally New Products and New Product Platforms are those cases. Considering Product Structure and Product Extensiveness, product of cross-company CD falls into the Product Structure of Integration, not limited to the Product Extensiveness (i.e., specialized and general usage of the current product). For example, even with product types of highly complex design architecture, such as airplanes, jet engine is not necessarily designed by CD. Such products can consider continuing the use of fine-tuned existing technology or extended by present platform, but without costly cross-company $\mathrm{CD}$. On the other hand, complex product types such as ERP software packages or operating systems (e.g., Microsoft Vista), while they belong to General Products, they may still have the need for cross-company CD to ensure enough multidisciplinary technologists involved in the product development to make the new product as complete and innovative as possible.

In the organization element, Project, Mediatory, and Functional organizations are potentially applicable. For information element, there are two alternative directions. One is in view of horizontal integration $\mathrm{CD}$, and the other is vertical integration $\mathrm{CD}$. The former one represents roles involved in performing the same or complementary functions within the same supply chain tier. For example, a system-level design can be carried out by three participants who belong to different corporations. The three corporations are around the globe and each takes the responsibility of product structure design, architecture design, and system integration assessment, respectively. All of them perform the tasks of the system-level design jobs at the same design stage and tier (not up-stream and down-stream relationship) but collaborate with each other. The latter one can apply the CD Information framework introduced in Figure 6, namely multiple-participant CD and CD in network. For instance, CD such as Derivative of Existing Product Platforms can be carried out by co-working with the manufacturing partners. If the participants include members from both multiple up-stream and down-stream companies, then it is the case of Network 
Cross-Company CD.

\subsection{Case Study}

In the case of Cross-Company CD, suppose the two dimensions of reference model are followed, decision aspect and design stage, to demonstrate how the reference model can help guide and present the $\mathrm{CD}$ activities among collaborating companies. In the following sections, the corresponding decision aspects are depicted for each design stage from incubation to verification stage under the scenario proposed by Chung and Lee [12].

\section{Incubation Stage (Planning and Concepting)}

Participants \& Product : in the first stage, participants involved are only the customer company, the injection molding company, and the mold company. Partnership selection process may take place within each of these three parties. In this case, however, the product is prone to be Product Platform Improved or Upgrade. Therefore, the injection molding company here may play the role of Compatible Player to the customer company, whereas the mold company may be the Minor Player.

Process : In Product Planning and Concepting, although the mold company is actively involved in the activity, only the customer and injection molding companies are responsible for the product concept development and specification definition. If it is the case of OEM, the injection molding company does gain the specific design drawing and specification information from the costumer company. If it is ODM or OBM, the role the injection molding company would play is relatively more important as specification/code definer. In the latter case, communication between the customer and the injection molding companies would be more frequent and intense.

Organization : In this stage, the mold company does not play significant role yet in the CD activity. Two main participants, the customer and the injection molding company cooperate more as a Functional organization, each playing their respective duty without dominating each other.

Information : As mentioned by Chung and Lee [12], information exchange platform is formed by XML, and the CD system architecture follows web-based mechanism. In the incubation stage, the information framework would follow the situation of Multiple-Tier (here it is two-tier) MonoParticipants (one company in each tier) CD.

\section{Proceeding Stage (System-Level Design and Detail Design)}

Participants : During the system-level and detail-level design, the mold company plays an important role in this stage. In this stage the injection molding and the mold companies have closer interaction. From the point of view of the customer, the mold company may now be considered a Minor Player, since it only executes the manufacturing activities. But it could be considered a Compatible Player by the injection molding company.

Product : Products in this stage would be plastic parts manufactured by the mold company with the specification and design drawings provided by the customer company, but may be verified or trimmed by the injection molding company which is authorized by the customer company to do so.

Process : through CORBA and platform formed by XML, the customer and the injection molding companies may cooperate with each other to analyze and verify the specification and design drawings to consider their manufacturability, quality, cost, etc. 


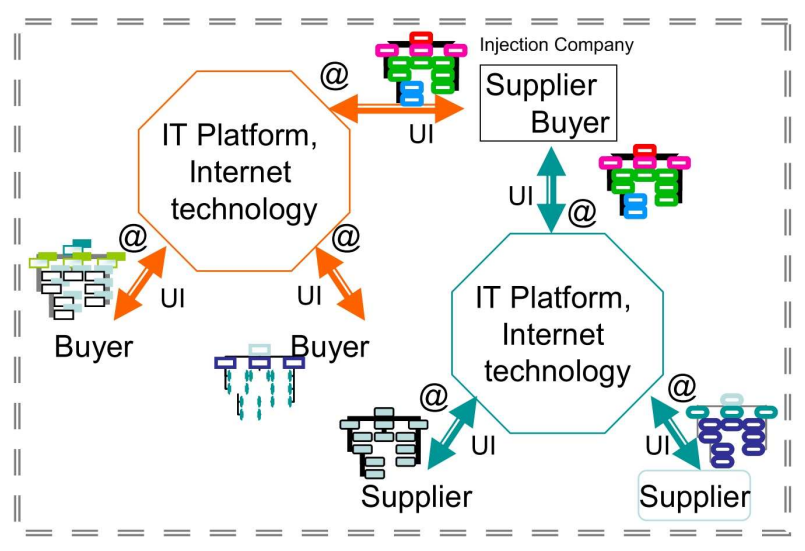

Figure 9: Information framework of $\mathrm{CD}$ in network

Organization : Organization type of this case under the system-level and detail-level design stage would fall into the Mediatory organization type, and the injection molding company plays the Mediator role.

Information : During the design static part, technologies used include XML to share information among design participants and application programs, RAMDES (RApid Mold Design Expert System) for mold design tool, PCIA (Parameter Connectivity Information Administrator) for evaluating the validities of parameters used in different dimensions and companies, client module and server module. In addition, the information system does provide a display of design information served by similar functions such as PDM or PLM system.

During the design operation, the CD system in this case relies on the four qualified factors mentioned in Section 2.2, which are data repository supported by XML, 3D virtualized tool for product design among various clients, connecting system by PCIA, and ASP sever to verify CAD system customized for mold design. Besides, the situation faced here will fall into the category of CD in network. The injection molding company plays the middle layer character facing both the layers of the customer (buyer) and the mold (supplier). Although Chung and Lee [12] do not deliver the detailed information regarding corresponding authority of each participant using the information sharing platform, the information gathered from the customer and the mold companies should be filtered by the injection molding company for its own purposes, or for other confidential considerations. Information exchange media (IT platform and Internet technology) would follow the mechanism depicted in Figure 9. Figure 9 indicates that the injection molding company plays both buyer and supplier roles relative to the mold company and to the customer company, respectively. It could co-design with the suppliers/buyers through IT platform and Internet technology.

\section{Verification Stage (Testing and Prototyping)}

Participants : In this stage, participants involved are basically the manufacturing and business divisions of the mold company, and may include some analysis and design divisions of the injection molding company. Meanwhile, design and analysis office of the mold company would support them to assure successful mold production. From another perspective, however, manufacturing and business offices play secondary roles to support design and analysis divisions to fulfill the order from the injection molding company.

Product : Product at this stage is basically the improved design objects and routine product development tasks that should be carried out by the manufacturing office of the mold company and be delivered 
on-time.

Process : The divisions of the mold company have to cooperate with each other to fulfill the quantity and quality specifications of the request orders from the injection molding company. The fulfillment of the process can be delivered by the mutually agreed protocols.

Organization : Organization applied here may be Project organization (Table 2).

Information : Divisions within the mold company can co-work on the same IT system or intranet platform to interchange information within different departments. Data repository such as product tracking system or PDM system and connecting system such as intranet communication platform may provide a channel for information sharing and update among the divisions. Although concurrent engineering could be implemented in the $\mathrm{CD}$, certain sequential activities still take place within the $\mathrm{CD}$ activities.

This case study has demonstrated the application of the CD reference architecture for the case of three participating companies. The three companies together, and each for its own purposes, can systematically use this CD reference architecture to analyze their respective and mutual requirements for the purpose of most effective collaboration. It is anticipated that effective collaboration would reduce conflicts and costs, support the quality of the design on which they collaborate, and also foster further productive collaboration among them. The case study demonstrates the proposed reference architecture can successfully conquer the challenging issues (Nos. 1, 2, 4, 5, 6 and 7) in Sections 1.4.

\section{Conclusions and Future Works}

Reference architecture for collaborative design has been defined and implemented. This reference architecture provides a new perspective for analyzing requirements for successful and effective $C D$, and dimensions to be considered when initiating a CD project. This architecture was designed to help decision-makers in dealing with implementation of a CD project or activity. The sliced CD reference model also serves as a guideline map for collaborating software system developers or people involved in the design collaboration to figure out their own functions and current progress of the group. Three dimensions included in the reference architecture are:

1. Decision aspect: five elements, including Participant, Product, Process, Organization, and Information.

2. Design stage: Planning and concepting, system-level design and detail design, and testing and prototyping

3. Collaboration scope: Cross-functional CD, Cross-company CD, Cross-industry CD

The architecture by demonstrating a case study already meets several major challenges facing collaborative design, including:

1. Adaptability to architecture changes;

2. Usability on heterogeneous information systems;

3. Capability to transmit message and data changes;

4. Rapid configuration;

5. Minimizing the impact of service changes;

6. Readiness for future expansion. 
An application of the CD reference architecture specified in the scope of cross-company is also developed in this research. This research demonstrates how to use the reference model (as a portion of the reference architecture) in developing design collaboration activities and how to specify the details of $\mathrm{CD}$ contents. As for future research, details specifications of each cube and the cube-cube relationships in the reference architecture are important issues. Detailed checking to understand whether the CD reference architecture meets all the challenges presented in Section 1.4 are also required.

\section{Acknowledgments}

The authors are thankful for financial support from research project NSC 98-2221-E-029019, National Science Council, Taiwan. Special thanks to Purdue University for pioneering the Purdue Enterprise Reference Architecture, PERA, which inspired the development of this research.

\section{Bibliography}

[1] J.A. Abdalla. A communication model for structural design objects. II: Performatives and protocols. Advances in Engineering Software, 37 (6): 393-405, 2006.

[2] A.J. Alvares, J.C.E. Ferreira. A system for the design and manufacture of feature-based parts through the Internet. nternational Journal of Advanced Manufacturing Technology, 35 (7-8): 646-664, 2008.

[3] B. Borja de Mozota. Design management: using design to build brand value and corporate innovation. New York: Allworth Press, 2003.

[4] A. Brelinghoven. Cooperative concurrency control for design environment. Proceedings EURO-DAC '95. Brighton, Great Britain: IEEE Computer Society Press, 1995: 308-313.

[5] H.-J. Bullinger, J. Warschat, J. Leyh, T. Cebulla. Planning and integration of product development. In: Salvendy G., editor. Handbook of industrial engineering: technology and operations management. New York: Wiley, 2001:1283-1294.

[6] J.A. Ceroni, A.A. Velasquez. Conflict detection and resolution in distributed design. Production Planning \& Control, 14 (8): 734-742, 2003.

[7] J.A. Ceroni, S.Y. Nof. Task parallelism in distributed supply organizations: a case study in the shoe industry. Production Planning \& Control, 16(5): 500-513, 2005.

[8] T.A. Chiang, A.J.C. Trappey, C.C. Ku. Using a knowledge-based intelligent system to support dynamic design reasoning for a collaborative design community. International Journal of Advanced Manufacturing Technology, 31 (5-6): 421-433, 2006.

[9] O. Chira, C. Chira, T. Roche, D. Tormey, A. Brennan. An agent-based approach to knowledge management in distributed design. Journal of Intelligent Manufacturing, 17 (6): 737-750, 2006.

[10] C. Chira, O. Chira. A Multi-Agent System for Design Information Management and Support. International Journal of Computers, Communications and Control, 1, Suppl. Issue, 2006.

[11] M.-L. Chiu. An organizational view of design communication in design collaboration. Design Studies, 23 (2): 187-210, 2002.

[12] J. Chung, K. Lee. A framework of collaborative design environment for injection molding. Computers in Industry, 47 (3): 319-337, 2002.

[13] Q. Hao, W.M. Shen, Z. Zhang, S.W. Park, J.K. Lee. Agent-based collaborative product design engineering: An industrial case study. Computers in Industry, 57 (1): 26-38, 2006.

[14] R.H. Hayes, S.C. Wheelwright, K.B. Clark. Dynamic manufacturing: creating the learning organization. New York: Free Press, 1988. 
[15] K. Holt. The nature of design process. In: Oakley M., editor. Design management: a handbook of issues and methods. Oxford, UK ; Cambridge, MA., USA: Blackwell Reference, 1990:195-198.

[16] C.C. Huang. A multi-agent approach to collaborative design of modular products. Concurrent Engineering-Research and Applications, 12 (1): 39-47, 2004.

[17] C.Y. Huang, S.Y. Nof. Development of integrated models for material flow - Design and control - a tool perspective. Robotics and Computer-Integrated Manufacturing, 14 (5-6): 441-454, 1998.

[18] Y. Jin, S.C.Y. Lu. Agent based negotiation for collaborative design decision making. CIRP Annals-Manufacturing Technology, 53 (1): 121-124, 2004.

[19] T. Keinonen. Introduction to concept design. In: Keinonen T., Takala R., editors. Product concept design: a review of the conceptual design of products in industry. London: Springer, 2006:1-31.

[20] N. Khanna, J.A.B. Fortes, S.Y. Nof. A formalism to structure and parallelize the integration of cooperative engineering design tasks. IIE Transactions, 30 (1): 1-15, 1998.

[21] M. Klein. Integrated support for cooperative design coordination: managing processes, conflicts and memories. In: Nof S.Y., editor. Information and Collaboration Models of Integration. Boston: Kluwer, 1994:435-459.

[22] M. Klein. Capturing Geometry Rationale for Collaborative Design. it 6th Workshop on Enabling Technologies Infrastructure for Collaborative Enterprises (WET-ICE '97), pp. 24-28, 1997.

[23] H.S. Ko, S.Y. Nof. Design of Collaborative e-Service Systems. In: Salvendy, G., W. Karwowski, editors, Introduction to Service Engineering, John Wiley \& Sons, Inc., 2009.

[24] A. Kusiak. Concurrent engineering: Issues, models, and solution approaches. In: Dorf, R.C, A. Kusiak editors. Handbook of Design, Manufacturing, and Automation, Wiley Inter-science, 1994: 35-49.

[25] M.A. Lara, S.Y. Nof. Computer-supported conflict resolution for collaborative facility designers. International Journal of Production Research, 41 (2): 207-233, 2003.

[26] J.S. Li, D.Z. Su. Support modules and system structure of web-enabled collaborative environment for design and manufacture. International Journal of Production Research, 46 (9): 2397-412, 2008.

[27] X. Liu, S. Raorane, M. Leu. A Web-based Intelligent Collaborative System for Engineering Design In: Li W.D., McMahon C., Ong S.K., Nee A.Y.C., editors. Collaborative Product Design and Manufacturing Methodologies and Applications. Springer London, 2007:37-58.

[28] Y. Luo. Cooperative Design in Building Construction In: Li W.D., Ong S.K., Nee A.Y.C., McMahon C., editors. Collaborative Product Design and Manufacturing Methodologies and Applications. London: Springer, 2007:93-108.

[29] M. Mahesh, S.K. Ong, A.Y.C. Nee. A web-based framework for distributed and collaborative manufacturing. In: Li W.D., Ong S.K., Nee A.Y.C., McMahon C., editors. Collaborative Product Design and Manufacturing Methodologies and Applications. London: Springer, 2007:137-148.

[30] F. Mervyn, A.S. Kumar, A.Y.C. Nee. Leveraging design process related intellectual capital-a key to enhancing enterprise agility. In: Li W.D., Ong S.K., Nee A.Y.C., McMahon C., editors. Collaborative Product Design and Manufacturing Methodologies and Applications, London: Springer, 2007: 71-90.

[31] S.S. Msanjila, H. Afsarmanesh. Trust analysis and assessment in virtual organization breeding environments. International Journal of Production Research, 46: 1253-1295, 2008. 
[32] S.Y. Nof. Collaborative control theory for e-work, e-production, and e-service. Annual Reviews in Control, 31(2): 281-92, 2007.

[33] H. Noori, W.B. Lee. Collaborative design in a networked enterprise: The case of the telecommunications industry. International Journal of Production Research, 42 (15): 3041-3054, 2004.

[34] J.H. Panchal, H.J. Choi, J.K. Allen, D.L. McDowell, F. Mistree. A systems-based approach for integrated design of materials, products and design process chains. Journal of Computer-Aided Materials Design, 14: 265-293, 2007.

[35] J.H. Panchal, M.G. FernĂĄndez, C.J.J. Paredis, J.K. Allen, F. Mistree. Leveraging Design Process Related Intellectual Capital. A Key to Enhancing Enterprise Agility. In: Li W.D., Ong S.K., Nee A.Y.C., McMahon C., editors. Collaborative Product Design and Manufacturing Methodologies and Applications. London: Springer, 2007:201-208.

[36] M. Pappas, V. Karabatsou, D. Mavrikios, G. Chryssolouris. Development of a web-based collaboration platform for manufacturing product and process design evaluation using virtual reality techniques. International Journal of Computer Integrated Manufacturing, 19 (8): 805-814, 2006.

[37] S. Pilemalm, P.O. Lindell, N. Hallberg, H. Eriksson. Integrating the Rational Unified Process and participatory design for development of socio-technical systems: a user participative approach. Design Studies, 28 (3): 263-288, 2007.

[38] H. Li, T.J. Williams. A Formalization and Extension of the Purdue Enterprise Reference Architecture and the Purdue Methodology, Report No. 158, Laboratory for Applied Industrial Control, Purdue University, http://citeseerx.ist.psu.edu/viewdoc/download?doi=10.1.1.25.6659\&rep=rep1\&type=pdf, 1994.

[39] V. Robin, B. Rose, P. Girard. Modelling collaborative knowledge to support engineering design project manager. Computers in Industry, 58 (2): 188-198, 2007.

[40] V. Robin, S. Sperandio, S. Blanc, P. Girard. Interactions modeling between factors influencing performance of the design process. International Conference on Engineering Design, ICED 2005. Melbourne, 2005.

[41] H.Y. Shiau, H.M. Wee. A distributed change control workflow for collaborative design network. Computers in Industry, 59 (2-3): 119-127, 2008.

[42] K. Slimani, C.F. Da Silva, L. Medini, P. Ghodous. Conflict mitigation in collaborative design. International Journal of Production Research, 44 (9): 1681-1702, 2006.

[43] D.B. Tang. An agent-based collaborative design system to facilitate active die-maker involvement in stamping part design. Computers in Industry, 54 (3): 253-271, 2004.

[44] J.P. Thomas, K.D. Baker. Knowledge representation for design. 1991 IEEE International Conference on Decision Aiding for Complex Systems. Charlottesville, VA 1991:1827 1832.

[45] L. Tian, J.Z. Chen, Q.Y. Wang, W.T. Hao, B.S. Tong. CoDesign Space: a collaborative design support system in a network environment. International Journal of Computer Integrated Manufacturing, 20 (2-3): 265-279, 2007.

[46] A.J.C. Trappey, D.W. Hsiao. Applying collaborative design and modularized assembly for automotive ODM supply chain integration. Computers in Industry, 59: 277-287, 2008.

[47] K.C. Tseng, H. Abdalla, E.M. Shehab. A Web-based integrated design system: its applications on conceptual design stage. International Journal of Advanced Manufacturing Technology, 35 (9-10): 1028-1040, 2008.

[48] K.T. Ulrich, S.D. Eppinger. Product design and development. McGraw-Hill/Irwin: Boston, 2004. 
[49] K.T. Ulrich, S.D. Eppinger. Product design and development. McGraw-Hill Higher Education: Boston, 2008.

[50] J.D. Velasquez, S.Y. Nof. Collaborative e-Work, e-Business, and e-Service. In: Nof, S.Y., editor, Handbook of Automation, Springer, 2009, 1549-1576.

[51] C. Wang, K. Li, H. Ghenniwa, W. Shen, Y. Wang. Real Time Distributed Shop Floor Scheduling: An Agent -Based Service-Oriented Framework. In: Li W.D., Ong S.K., Nee A.Y.C., McMahon C., editors. Collaborative Product Design and Manufacturing Methodologies and Applications. London: Springer, 2007:175-197.

[52] J.P. Witzerman, S.Y. Nof. Tool Integration for Collaborative Design of Manufacturing Cells. International Journal of Production Economics, 38 (1): 23-30, 1995.

Chin-Yin Huang is Associate Professor in the Department of Industrial Engineering and Enterprise Information at Tunghai University, Taiwan. He also serves as Director of the Executive Master Program for Health Administration. He received his Ph.D. from Purdue University, USA. His research interests include agent-based integrated systems, distributed production planning, process optimization in plastic injection molding, and medical data analysis. His recent book, Industrial Engineering and Management was published in 2004. He is a member of CIIE, IFAC, IFPR-APR, and SOCOLNET.

Tung-Ting Yang is a Manager of Product Manufacturing in HTC. She received her BA degree from National Chengchi University and an MSIE degree from Tunghai University. Her research interests include new product development and financial management.

Wu-Lin Chen is Assistant Professor in the Department of Computer Science and Information Management, Providence University, Taiwan. He received his Ph.D. from Purdue University. His research interests include supply chain optimization, stochastic systems, and manufacturing process optimization.

Shimon Y. Nof is Professor of Industrial Engineering and director of the NSF-industry supported PRISM Center (Production, Robotics and Integration Software for Manufacturing \& Management) at Purdue University. He has held visiting positions at MIT and universities in Chile, EU, Hong Kong, Israel, Japan, and Mexico. Received his B.Sc. and M.Sc. in Industrial Engineering \& Management (Human-Machine Systems), Technion, Haifa, Israel; Ph.D. in Industrial \& Operations Engineering (Production Analytics), University of Michigan, Ann Arbor. Among his honors: Inaugural member of Purdue's Book of Great Teachers (1999); the Engellerger Medal for Robotics Education (2002), Fellow of IIE, recent President and former Secretary General of IFPR, recent Chair of IFAC CC-Mfg. \& Logistics Systems. Dr. Nof has published over 400 articles on production engineering and information technology, and is the co-author/editor of ten books, including the Handbook of Industrial Robotics (Wiley, 1985; 2nd Edition 1999) and the International Encyclopedia of Robotics (Wiley, 1988), both winners of the "Most Outstanding Book in Science and Engineering" award by the Association of American Publishers, Industrial Assembly (Chapman \& Hall, 1997, co-authored with H-J Warnecke and W. E. Wilhelm), and the Handbook of Automation (Springer, 2009). 